\title{
A ATIVIDADE RESPIRATÓRIA MITOCONDRIAL É UM BOM PARÂMETRO PARA A LESÃO POR ISQUEMIA E REPERFUSÃO HEPÁTICA?
}

\author{
Luiz Eduardo Correia MIRANDA ${ }^{1}$, Fernanda VIARO ${ }^{1}$, \\ Reginaldo CENEVIVA ${ }^{2}$ e Paulo Roberto Barbosa ÉVORA ${ }^{1}$
}

RESUMO - Racional - A atividade respiratória das mitocôndrias está associada à lesão por isquemia e reperfusão do fígado. Objetivo - Investigar in vitro se há obrigatoriedade de impedimento da respiração mitocondrial para que a lesão por isquemia e reperfusão do fígado possa ser detectada. Materiais e Métodos - Vinte e quatro cães de ambos os gêneros foram divididos nos seguintes grupos: controle, cães operados sem sofrer isquemia ou reperfusão hepática; $\mathrm{I}_{60}$, cães submetidos a 60 minutos de isquemia do fígado; $I_{30} / R_{60}$, cães submetidos a 30 minutos de isquemia e 60 minutos de reperfusão do fígado e $I_{45} / R_{120}$, cães submetidos a 45 minutos de isquemia e 120 de reperfusão do fígado. Amostras de fígado foram obtidas para dosagem de malondialdeído, para estudo da respiração mitocondrial por meio de traços polarográficos e para avaliação do potencial de membrana mitocondrial. Sangue foi obtido para dosagem de transaminases e desidrogenase lática. Resultados - O grupo $\mathrm{I}_{45} / \mathrm{R}_{120}$ apresentou evidente aumento dos valores de transaminases, desidrogenase lática, aumento dos valores de malondialdeído e tendência à diminuição da respiração mitocondrial estimulada por adenosina difosfato, sem haver prejuízo irreversível para a fosforilação oxidativa ou para o potencial de membrana mitocondrial. Conclusão - A lesão por isquemia e reperfusão do fígado do cão pode ser documentada sem que haja prejuízo demonstrável para a função mitocondrial. Dados referentes à respiração mitocondrial podem não mostrar diferenças significativas em relação aos controles, mesmo em situações de evidente lesão tecidual por isquemia e reperfusão do fígado.

DESCRITORES - Mitocôndria hepática. Traumatismo por reperfusão. Fosforilação oxidativa. Fígado.

\section{INTRODUÇÃO}

Embora o transplante hepático tenha se tornado o tratamento padrão para os casos de insuficiência hepática terminal $^{(20)}$, a disfunção do enxerto ainda é importante causa de morbidade e mortalidade pós-operatória. Ao se restabelecer o fluxo sangüíneo ao órgão transplantado, provoca-se o agravamento da lesão sofrida durante o período de isquemia extracorpórea ${ }^{(4,9)}$.

A fosforilação oxidativa é processo que sofre as graves conseqüências da reperfusão. Uma vez que a cadeia respiratória está localizada nas membranas mitocondriais, e sendo as membranas celulares importantes alvos da lesão por radicais livres originados durante o período de reperfusão, é natural supor que a destruição das membranas celulares resultará no impedimento da fosforilação oxidativa, fenômeno que pode ser facilmente documentado em laboratório ${ }^{(7)}$.

As alterações mitocondriais estão claramente associadas à lesão da microcirculação hepática, já que o restabelecimento do fluxo sangüíneo na microcirculação é necessário para a reabilitação da respiração mitocondrial ${ }^{(13)}$. Admite-se que o sofrimento da mitocôndria durante o período de reperfusão gere os radicais livres que resultarão ou agravarão a lesão celular ${ }^{(6)}$ : durante a isquemia, há grave diminuição dos componentes da cadeia respiratória. Durante a reperfusão, ocorre produção de ânion superóxido. O ânion superóxido intramitocondrial, incapaz de se difundir para fora da mitocôndria, gera peróxido de hidrogênio por meio da ação de enzima Mn-superóxido dismutase. O peróxido de hidrogênio difunde-se para o citosol. O resultado da geração de superóxido intramitocondrial será o aumento da concentração de peróxido de hidrogênio em toda a célula. Esse irá reagir com grupos hemes de citocromos citosólicos e intramitocondriais, gerando espécies oxidativas extremamente reativas e capazes de iniciar as lesões observadas.

Embora os efeitos da reperfusão sejam poderosos, as células possuem eficiente aparato enzimático antioxidante, que é capaz de neutralizar, em parte, os

Trabalho realizado no Laboratório de Função Endotelial do Departamento de Anatomia e Cirurgia da Faculdade de Medicina de Ribeirão Preto, Universidade de São Paulo, Ribeirão Preto, SP ${ }^{1}$ Laboratório de Função Endotelial, Departamento de Anatomia e Cirurgia; ${ }^{2}$ Disciplina de Gastrocirurgia, Faculdade de Medicina de Ribeirão Preto, Universidade de São Paulo, Ribeirão Preto, SP.

Endereço para correspondência: Dr. Luiz Eduardo Correia Miranda - Rua Dhália - 74 - apt. 1802 - Boa Viagem - 51020-290 - Recife, PE E-mail: lecmiranda@ig.com.br. 
efeitos da ação de radicais livres. Esgotados os mecanismos de defesa celular, a ação de radicais livres provocará os eventos fisiopatológicos que resultarão na morte celular ${ }^{(11)}$. As alterações mitocondriais que ocorrem durante o período de reperfusão hepática não são responsáveis pela morte celular, mas são consideradas como bons indicadores das lesões por isquemia e reperfusão ${ }^{(7)}$ por estarem intimamente associadas à lesão da microcirculação hepática, uma vez que sua recuperação é de vital importância para a reabilitação da função celular ${ }^{(13)}$. As mitocôndrias agravam o sofrimento celular e sofrem as conseqüências da reperfusão. Não está claro, entretanto, se a lesão celular pode ser documentada em um momento em que as mitocôndrias ainda são capazes de gerar adenosina trifosfato (ATP). Se isso for possível, a atividade respiratória mitocondrial não pode ser usada como um indicador universal da lesão celular.

O objetivo do presente estudo foi investigar se pode haver atividade respiratória mitocondrial detectável em laboratório durante a lesão por isquemia e reperfusão do fígado.

\section{MATERIAL E MÉTODOS}

Este estudo foi realizado de acordo com as normas para experimentação em animais da Universidade de São Paulo.

Cães mestiços de ambos os gêneros, livres de verminose por tratamento com prazinquantel (drontal plus, $660 \mathrm{mg}$, em duas doses separadas por 15 dias), com peso variando de 15 a $25 \mathrm{~kg}$, fornecidos pelo biotério central da Faculdade de Medicina de Ribeirão Preto da Universidade de São Paulo, Ribeirão Preto, SP, foram aleatoriamente distribuídos nos seguintes grupos: grupo controle: seis cães, grupo $\mathrm{I}_{60}$, seis cães submetidos a isquemia do fígado por 60 minutos; grupo $\mathrm{I}_{30} / \mathrm{R}_{60}$, seis cães submetidos a 30 minutos de isquemia e a 60 minutos de reperfusão do fígado; grupo $\mathrm{I}_{45} / \mathrm{R}_{120}$, seis cães submetidos a 45 minutos de isquemia e a 120 minutos de reperfusão do fígado.

Os animais receberam cetamina por via intra-muscular (ketamin, $50 \mathrm{mg} / \mathrm{mL}$, Laboratório Cristália, na dose de $5 \mathrm{mg} / \mathrm{kg}$ )) como pré-anestésico, sendo a seguir, anestesiados com pentobarbital sódico ( $25 \mathrm{mg} / \mathrm{kg}$; bolus endovenoso; Abbot Laboratórios), por meio de veia periférica, intubados com sonda traqueal com balão (cânula Rush) e ventilados com $100 \%$ de oxigênio por respirador a pressão positiva. Procedeu-se à monitorização da pressão arterial média pela cateterização da artéria femoral direita com sonda uretral 8 Fr e da temperatura corporal por termômetro retal. Amostras de sangue foram colhidas para dosagens de transaminases, bilirrubinas, fosfatase alcalina e desidrogenase lática (DHL) no início e ao término da operação. Durante o período operatório os animais receberam soro fisiológico endovenoso por veia periférica $(20 \mathrm{~mL}$ por $\mathrm{kg}$ de peso corporal por hora) e anestésicos para manter a pressão arterial estável e o cão em plano anestésico.

Os animais foram submetidos a laparotomia mediana e colocação de pinça vascular no pedículo hepático. Após o período desejado de isquemia, a pinça vascular foi retirada sob visão direta e no grupo $\mathrm{I}_{30} / \mathrm{R}_{60}$ e grupo $\mathrm{I}_{45} / \mathrm{R}_{120}$ os animais foram submetidos ao período de reperfusão desejado.
Os animais do grupo $\mathrm{I}_{60}$ foram submetidos apenas ao período de isquemia, sem período de reperfusão. Os animais do grupo controle foram submetidos ao mesmo procedimento anestésico que os demais animais e a laparotomia sem clampagem do pedículo hepático por 165 minutos. Após o término do procedimento, os animais foram rapidamente exsangüinados pelo cateter da artéria femoral e amostras do fígado foram retiradas para avaliação do malondialdeído (MDA) e avaliação da função mitocondrial. Amostras de sangue foram colhidas para dosagem de transaminases e DHL.

\section{Avaliação da taxa de lipoperoxidação hepática}

As substâncias que reagem ao ácido tiobarbitúrico são, em sua maioria, produtos da peroxidação lipídica, sendo a dosagem dessas substâncias usada para monitoramento da taxa de lipoperoxidação. A dosagem foi realizada de acordo com o método descrito por BUEGE e AUSSI ${ }^{(1)}$. A determinação da peroxidação lipídica usou como reagente a solução TCA-TBAHCL, ou seja, 15\% w/v de ácido tricloacético, 0,375\% w/v de ácido tiobarbitúrico em $0,25 \mathrm{~N}$ de ácido hidroclórico. A dosagem de proteínas no fígado foi feita por meio do método de LOWROY at al. ${ }^{(15)}$.

\section{Avaliação da função mitocondrial ${ }^{(2)}$}

A amostra de fígado foi lavada com soro fisiológico e colocada em becker com meio de homogenização (sacarose 250 mM, EGTA 1 mM e Hepes-KOH 10 mM, pH 7,2) para secção do fígado em pequenos fragmentos com tesoura. Os fragmentos foram homogenizados em homogenizador do tipo Potter Elvhjem por 3 segundos, com intervalos de 1 minuto entre cada sessão de homogenização, para o total de três sessões. A amostra foi, a seguir, centrifugada a $750 \mathrm{~g}$ por 5 minutos; centrifugação do sobrenadante do processo anterior por 10 minutos a $12.000 \mathrm{~g}$. O sedimento obtido pelo processo anterior foi suspenso em $10 \mathrm{~mL}$ de meio contendo sacarose $250 \mathrm{mM}$, EGTA 0,3 mM e Hepes-KOH $10 \mathrm{mM}$, pH 7,2 e centrifugado por $15 \mathrm{~min}$ a $4320 \mathrm{~g}$. O sedimento obtido foi suspenso em $1 \mathrm{~mL}$ do meio contendo sacarose $250 \mathrm{mM}$ e Hepes-KOH 10 mM, pH 7,2.

Uma amostra do preparado obtido foi usada para dosagem de proteínas. Os estudos com as mitocôndrias energizadas foram feitos dentro de período máximo de 2 horas após o isolamento. Todas as etapas foram realizadas à temperatura constante de $4^{\circ} \mathrm{C}$.

\section{Determinação da proteína da fração mitocondrial}

A concentração de proteína mitocondrial foi determinada espectrofotometricamente pelo método do Biureto ${ }^{(12)}$, modificado pela adição de colato $1 \%$, utilizando BSA $1 \%$ como padrão.

\section{Determinação do consumo de oxigênio pelas mitocôndrias energizadas}

O consumo de oxigênio pelas mitocôndrias energizadas foi determinado polarograficamente a $30^{\circ} \mathrm{C}$ por meio de oxígrafo de Gylson (Medical Eletronics EUA), acoplado a eletrodo tipo Clarck. O meio de respiração $(1,3 \mathrm{~mL})$ é composto por sacarose 1,25 mM, cloreto de potássio $65 \mathrm{mM}$, fosfato de potássio $2 \mathrm{mM}$, cloreto de magnésio $1 \mathrm{mM}$, EGTA $0,1 \mathrm{mM}$ e Hepes-KOH 10 mM, e adicionado succinato $5 \mathrm{mM}, \mathrm{pH} 7,4$. 
Utilizaram-se $2 \mathrm{mg}$ de proteína mitocondrial. O estado 3 da respiração mitocondrial (estado ativado) foi obtido pela adição de 200 nmoles de ADP às mitocôndrias energizadas. A relação entre a velocidade de respiração após a adição de ADP (estado 3) e a velocidade do estado basal (estado 4), obtida após consumo de ADP, forneceu a razão de controle respiratório (RCR). Os resultados obtidos dos estados 3 e 4 foram expressos em número átomos de oxigênio/mg de proteína mitocondrial/minuto.

\section{Determinação do potencial elétrico da membrana mitocondrial interna}

O potencial elétrico de membrana das mitocôndrias (PM) foi determinado espectrofluorimetricamente utilizando $5 \mu \mathrm{M}$ de safranina $\mathrm{O}$ como indicador, em fluorímetro tipo SLM-AMINCO em comprimentos de onda de $495 \mathrm{~nm}$ para excitação e $586 \mathrm{~nm}$ para emissão ${ }^{(5)}$. As mitocôndrias foram preparadas em meio contendo sacarose $200 \mathrm{mM}$, fosfato de potássio $2 \mathrm{mM}$, EGTA $0,03 \mathrm{mM}$, cloreto de magnésio $1 \mathrm{mM}$ e Hepes- $\mathrm{KOH} 10 \mathrm{mM}$, em pH 7,2, sendo o potencial de membrana gerado pela adição de succinato $5 \mathrm{mM} /$ Rotenona $4 \mu \mathrm{M}$. Após a estabilização do potencial de membrana, adicionou-se $1 \mu \mathrm{M}$ do desacoplador FCCP (carbonil cianeto ptrifluoro-metoxi fenilhidrazona $\left.{ }^{(3)}\right)$. Os resultados obtidos (unidade relativa de fluorescência) foram convertidos em $\mathrm{mV}$, a partir de curva de calibração. Todos os reagentes usados nessa fase dos experimentos foram adquiridos das empresas Sigma ou Merck.

\section{Determinação dos valores das trasaminases}

Para a determinação da atividade da alanina aminotransferase (ALT) e aspartato aminotransferase (AST) foi utilizado kit comercial fornecido pela empresa CELM Cia. Equipadora de Laboratórios Modernos, Barueri, SP

Para determinação dos valores de DHL foi utilizado método cinético - UV (International Federation of Clinical Chemistry, 1980). O teste no soro sangüíneo determina a quantidade de enzima encontrada no coração, fígado, rins, cérebro, músculo esquelético e glóbulos vermelhos. O kit utilizado foi obtido da empresa Labormed (Guarulhos, SP).

\section{Análise estatística}

Os valores correspondentes aos resultados das provas bioquímicas, dosagem do MDA e valores referentes aos parâmetros de respiração mitocondrial são expressos como média aritmética e erro-padrão da média. Em todos os experimentos, $\mathrm{n}$ significa o número de animais dos quais amostras de fígado para dosagem de MDA e avaliação da respiração mitocondrial, ou as amostras de sangue foram obtidos. Para a análise estatística, foi utilizado teste de análise de variância (ANOVA one-way), complementado pelo teste de Bonferroni para observações não-pareadas. Os cálculos foram feitos por meio do programa para computador GraphPAd Prism 3.0. Os valores foram considerados significantes quando $P<0,05$.

\section{RESULTADOS}

\section{Respiração mitocondrial}

A análise dos resultados referentes ao estado de respiração ativada (estado 3), respiração mitocondrial basal (estado 4),
RCR, relação ADP:O e potencial de membrana mitocondrial não mostrou diferenças com significância estatística entre os grupos estudados (Tabela 1).

TABELA 1 - Dados referentes à respiração mitocondrial. Estado 3 corresponde ao estado de respiração mitocondrial ativada; estado 4 corresponde ao estado de respiração mitocondrial basal

\begin{tabular}{lccccc}
\hline Grupo & Estado 3 & Estado 4 & RCR & ADP:O & PM \\
\hline Controle & $49,37 \pm 5,94$ & $19,47 \pm 3,77$ & $2,70 \pm 0,20$ & $1,15 \pm 0,15$ & $148 \pm 0,2$ \\
$\mathrm{I}_{60}$ & $55,50 \pm 11,43$ & $20,08 \pm 5,68$ & $3,0 \pm 0,30$ & $0,87 \pm 0,10$ & $148 \pm 1,3$ \\
$\mathrm{I}_{30} \mathrm{R}_{60}$ & $39,250 \pm 9,53$ & $16,62 \pm 4,91$ & $2,72 \pm 0,48$ & $1,150 \pm 0,20$ & $150 \pm 1,24$ \\
$\mathrm{I}_{45} \mathrm{R}_{120}$ & $35,87 \pm 4,73$ & $19,20 \pm 3,85$ & $2,10 \pm 0,40$ & $1,120 \pm 0,18$ & $149 \pm 0,50$ \\
\hline $\begin{array}{l}\mathrm{RCR}=\text { razão de controle respiratório; ADP:O = corresponde à razão entre ADP e oxigênio; } \\
\mathrm{PM}=\text { potencial de membrana mitocondrial }\end{array}$ &
\end{tabular}

\section{ALT, AST e DHL}

Houve diferença com significância estatística entre os valores de transaminases $(P<0,01)$ e DHL $(P<0,05)$ entre o grupo controle e o grupo $\mathrm{I}_{45} / \mathrm{R}_{120}$ (Tabela 2$)$.

TABELA 2 - Resultados das dosagens de ALT, AST e DHL segundo os grupos estudados. Houve diferença com significância estatística entre o grupo controle e o grupo $\mathrm{I}_{45} / \mathrm{R}_{120}$ * para as dosagens de ALT e AST $(\mathrm{P}<0,01)$, e para a dosagem de DHL $(P<0,05) ; \mathrm{n}=6$ para cada grupo

\begin{tabular}{lccc}
\hline GRUPOS & ALT & AST & DHL \\
\hline Controle & $74,7 \pm 22,8$ & $119,0 \pm 31,7$ & $285,7 \pm 51,6$ \\
$\mathrm{I}_{60}$ & $132,8 \pm 66.0$ & $156,20 \pm 49,20$ & $272,20 \pm 205,10$ \\
$\mathrm{I}_{30} \mathrm{R}_{60}$ & $380,67 \pm 185,6$ & $278,3 \pm 93,5$ & $570,0 \pm 300,0$ \\
$\mathrm{I}_{45} \mathrm{R}_{120}$ & $2.989,0 \pm 1056,0^{*}$ & $1.268,0 \pm 371,0^{*}$ & $2.887,0 \pm 1213^{*}$ \\
\hline
\end{tabular}

\section{Lipoperoxidação}

Os valores referentes às dosagens das substâncias reagentes ao ácido tiobarbitúrico (SRATB) mostraram diferenças com significância estatística entre o grupo $\mathrm{I}_{45} / \mathrm{R}_{120}$ e os grupos controle e $\mathrm{I}_{60}, P<0,05$ (Figura 1).

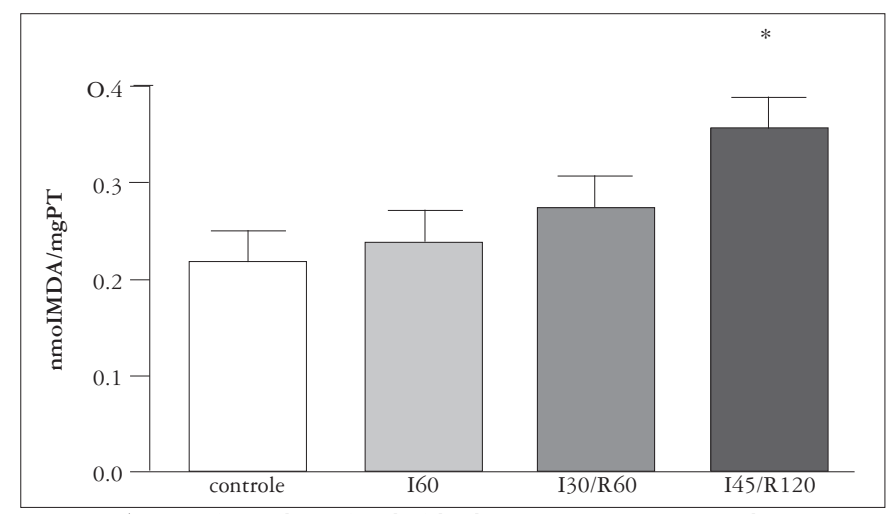

FIGURA 1 - Valores de malondialdeído em nmoL MDA/mg de proteínas em fígado de cão segundo os grupos estudados. Há diferença com significância estatística entre o grupo $\mathrm{I}_{45} / \mathrm{R}_{120}$ e os grupos controle e $\mathrm{I}_{60}, \mathrm{P}<0,05$ 


\section{DISCUSSÃO}

A lesão por isquemia e reperfusão do fígado é fenômeno pouco compreendido e motivo de grande número de importantes publicações científicas. Há vários métodos para avaliar e quantificar a lesão. As dosagens séricas de transaminases e DHL são parâmetros clássicos de lesão dos hepatócitos e são usadas praticamente em todos os trabalhos que têm como objetivo o estudo da lesão de isquemia e reperfusão, pois são de fácil reprodução e baixo custo.

Em grande número de trabalhos, os animais são submetidos desde poucos até 120 minutos de isquemia por períodos de reperfusão que variam de minutos até vários dias, com os mais variados objetivos.

Ratos submetidos a 45 minutos de isquemia passam a apresentar aumentos significativos das transaminases, já aos 15 minutos de reperfusão e aos 60 chegam a apresentar valores 30 vezes maiores que os valores basais ${ }^{(10)}$. Após 60 ou 90 minutos de isquemia apresentam maior aumento das transaminases, entre 1 e 3 horas de reperfusão. No presente trabalho, o grupo $\mathrm{I}_{30} / \mathrm{R}_{60}$ mostrou aumento dos seus valores séricos, sem significância estatística com relação aos controles. Entretanto, o grupo $\mathrm{I}_{45} / \mathrm{R}_{120}$ mostrou claro aumento dos valores de transaminases, semelhantes aos publicados na literatura, evidenciando que o modelo aqui utilizado foi suficiente para induzir lesão celular por isquemia e reperfusão do fígado.

A literatura mostra dados conflitantes com relação a lipoperoxidação no fígado reperfundido, havendo estudos bem conduzidos que sugerem ser pouco provável que a peroxidação de lipídios seja o principal fator responsável pela lesão do parênquima hepático, embora não se possa excluir que a lipoperoxidação seja o mecanismo de lesão em compartimentos limitados do fígado, por exemplo, células de Kupffer, neutrófilos e célular endoteliais ${ }^{(18)}$.

No presente estudo documentou-se aumento da geração de substâncias reativas ao ácido tiobarbitúrico, diretamente proporcional ao tempo de isquemia e reperfusão, com aumento significativo apenas no grupo $\mathrm{I}_{45} / \mathrm{R}_{120}$. São resultados concordantes com os observados por MA ${ }^{(16)}$, que sugerem que a extensão da lesão por isquemia e reperfusão está correlacionada ao conteúdo de MDA nos tecidos reperfundidos, e com a proposição de YOSHIKAWA et al. ${ }^{(22)}$ de que as espécies reativas de oxigênio e a peroxidação de lipídios têm importante papel na lesão por isquemia e reperfusão do fígado. A metodologia empregada nesse estudo não permite distinguir se os valores aumentados de MDA no grupo $I_{45} / R_{120}$ são causados pela peroxidação de lipídios de hepatócitos ou de outras células (células de Kupffer e leucócitos), mais vulneráveis a esse tipo de lesão por não possuírem as defesas antioxidantes naturais dos hepatócitos. Os presentes resultados indicam que há aumento da lipoperoxidação no fígado reperfundido, utilizando-se o modelo aqui proposto, mas não permitem afirmar que a peroxidação de lipídios seja o mecanismo principal da lesão do parênquima hepático.

Pode-se medir o consumo de $\mathrm{O}_{2}$ em mitocôndrias isoladas por meio de traços polarográficos. Esses traços refletem o estímulo do consumo de $\mathrm{O}_{2}$ (estado 3 ) obtido pela adição de pequena quantidade de ADP, seguido por diminuição na taxa respiratória devido ao consumo do ADP (estado 4). Essa seqüência pode ser repetida por outras adições de ADP, até que ocorra o esgotamento do $\mathrm{O}_{2}$ (estado 5). A relação entre a taxa de respiração ativa (estado 3) e de repouso (estado 4) é referida como RCR e é medida da certeza do acoplamento entre a transferência de elétrons pela cadeia respiratória e a fosforilação oxidativa, indicando a qualidade da preparação mitocondrial e sua capacidade em acelerar a respiração sob condições de demanda de energia, conservada a energia livre das reações de óxido-redução na forma de $\operatorname{ATP}^{(8)}$. Valores baixos de RCR, comparados aos respectivos controles, indicam alterações em um ou mais componentes da cadeia respiratória e, portanto, do estado energético celular ${ }^{(14)}$.

A regulação da taxa respiratória de um tecido pela oferta de ADP é situação fisiológica normal. Quando o tecido é submetido a isquemia total, as reservas de ATP continuam sendo convertidas a $\mathrm{ADP}+\mathrm{Pi}$ e as fosfocreatinas são convertidas a creatina, liberando fosfatos de alta energia. Se há acúmulo de ADP, há estímulo à respiração, que não pode ser ativada, pois não há oferta de $\mathrm{O}_{2}$. A taxa de fosforilação diminuirá, não se restabelecendo os estoques celulares de $\mathrm{ATP}^{(19)}$, indispensáveis para a manutenção da integridade e para o exercício da função celular. O ATP é produzido pela mitocôndria e a lesão mitocondrial pode levar à morte celular, portanto, a concentração de ATP é importante parâmetro de viabilidade celular ${ }^{(21)}$.

Os resultados encontrados indicam que não há prejuízo para a respiração celular em estado de repouso (estado de ausência de ADP) das mitocôndrias. O estudo dos valores do estado 3 (respiração ativada por ADP) mostra diminuição dos valores de consumo de $\mathrm{O}_{2}$ se as mitocôndrias são estimuladas com ADP. Embora haja clara tendência para a diminuição dos valores referentes ao estado 3, o tratamento estatístico por meio de análise de variância não mostrou diferenças entre os valores encontrados. Como resultado disso, a RCR também não mostrou diferenças significantes. GONZALEZ-FLECHA et al. ${ }^{(6)}$ documentaram diminuição significativa dos valores relativos ao estado 3 somente após 120 minutos de isquemia sem reperfusão, ou 60 minutos de isquemia seguidos por 30 minutos de reperfusão em fígados de ratos, e nenhuma diminuição dos valores relativos ao estado 4, mesmo após 180 minutos de isquemia, ou 180 minutos de isquemia seguidos por 30 minutos de reperfusão. São valores próximos aos observados neste experimento.

Por que não houve impedimento da atividade respiratória mitocondrial, mesmo no grupo em que houve clara lesão celular? É possível que, se os cães tivessem sofrido isquemia por tempo pouco mais prolongado, as lesões mitocondriais fossem mais evidentes no grupo $\mathrm{I}_{45} / \mathrm{R}_{120}$. Durante o período de isquemia, a importante diminuição na oferta de $\mathrm{O}_{2}$ para a cadeia respiratória limita a fosforilação oxidativa e a peroxidação lipídica. A capacidade respiratória dos tecidos nessas condições está perigosamente diminuída e as reservas de ATP não podem ser refeitas. Durante a reperfusão, a oferta de $\mathrm{O}_{2}$ permite que se restabeleça o metabolismo oxidativo, e também o aparecimento do estresse oxidativo. Seguramente, a gravidade do estresse oxidativo depende do tempo de isquemia. Em fígados de ratos, 60 minutos de isquemia sem hipotermia resultam em lesão celular reversível e o consumo de $\mathrm{O}_{2}$ retorna aos valores basais quando a oferta de $\mathrm{O}_{2}$ é restabelecida. Tempos maiores de isquemia (120-180 minutos) seguidos por reperfusão, resultarão em lesão celular irreversível ${ }^{(6)}$. 
Esses achados são compatíveis com as observações do presente estudo. Os valores relativos ao estado 3 não mostraram diferenças significativas porque o tempo de isquemia foi relativamente curto, embora tenha sido possível observar a tendência à diminuição do consumo de $\mathrm{O}_{2}$ na presença de $\mathrm{ADP}$, à medida que se aumentou o tempo de reperfusão. A diminuição da utilização do $\mathrm{O}_{2}$ mediante a oferta de ADP reflete o grau de impedimento funcional da cadeia respiratória como resultado da lesão por isquemia e reperfusão.

O potencial elétrico da membrana mitocondrial $(\Delta \Psi)$ pode ser aferido utilizando a mesma fração mitocondrial usada para determinação do consumo de $\mathrm{O}_{2}$ (método polarográfico). A membrana interna atua como sistema polarizado internamente com cargas negativas, que funcionam como sítios de ligação para corantes lipofílicos, por exemplo a safranina ${ }^{(3)}$. É possível avaliar $\Delta \Psi$ quantificando o número de sítios de ligação. A intensidade de fluorescência indica, de maneira inversamente proporcional, o grau de energização da membrana interna, ou seja, o potencial de membrana. Uma vez estabilizado o $\Delta \Psi$, adiciona-se um desacoplador, o protonóforo FCCP [carbonil cianeto $\rho$-(trifluoro-metoxi) fenilhidrazona $]^{(5)}$. Esses ácidos lipossolúveis fracos podem transpor a barreira lipídica da membrana mitocondrial sem transitar pela ATP-sintetase. Depois de entrar na matriz mitocondrial na forma protonada, por outra via para o fluxo de $\mathrm{H}^{+}$que não a da ATP sintetase, eles se dissociam do próton. Esse fato elimina o gradiente de prótons gerado pela cadeia transportadora de elétrons e, portanto, elimina o potencial de membrana. Há interrupção da síntese de ATP sem bloquear a captação de $\mathrm{O}_{2}$ pois tanto a oxidação de substratos, quanto o transporte de elétrons e o bombeamento de $\mathrm{H}^{+}$continuam, mesmo na ausência de $\mathrm{ADP}^{(14,17,19)}$. O potencial de membrana é avaliado em fluorímetro com comprimentos de onda de $495 \mathrm{~nm}$ para excitação e $586 \mathrm{~nm}$ para emissão, sendo o indicador usado a safranina O. Os valores obtidos são comparados a valores controles e são apresentados como medida fluorimétrica equivalente ao potencial de membrana mitocondrial interna.

Os resultados do presente estudo não mostraram alterações no potencial de membrana celular das mitocôndrias, achado que pode ser facilmente explicado pelos resultados obtidos nos parâmetros de respiração celular. Se não houve diferenças significativas nos parâmetros de respiração celular, o resultado observado é o esperado.
Esses resultados não contradizem a teoria mitocondrial, que explica a lesão celular causada pela geração de radicais livres pela mitocôndria reperfundida. $\mathrm{O}$ fato das mitocôndrias não sofrerem impedimento da fosforilação oxidativa, significativamente demonstrável no grupo $I_{45} R_{120}$, não significa que não tenha havido geração de radicais livres pelas mitocôndrias reperfundidas, capazes de causar a lesão celular observada, uma vez que o método utilizado nesse experimento não avaliou a geração de radicais livres pelas mitocôndrias reperfundidas.

A interpretação dos dados obtidos permite afirmar que, embora se possa observar lesão de hepatócitos com extravasamento de enzimas no grupo $\mathrm{I}_{45} / \mathrm{R}_{120}$ e tendência à diminuição dos valores relativos ao estado 3 proporcional ao tempo de isquemia e reperfusão, não houve lesão mitocondrial suficiente nesse grupo para que diferenças significantes entre os grupos estudados fossem documentadas. As mitocôndrias ainda eram capazes de gerar ATP, mesmo com evidente sofrimento celular. Os resultados sugerem que embora tenha havido lesão de hepatócitos no grupo $I_{45} / R_{120}$, não houve prejuízo irreversível para a fosforilação oxidativa.

\section{CONCLUSÃO}

A análise dos dados pelos instrumentos matemáticos escolhidos, dentro das condições em que esse experimento foi realizado, permite concluir que a lesão por isquemia e reperfusão do fígado de cães pode ser documentada sem que haja prejuízo demonstrável para a função mitocondrial.

Dados referentes à respiração mitocondrial podem não mostrar diferenças expressivas em relação aos controles, mesmo em situações de evidente lesão tecidual por isquemia e reperfusão do figado. Essa observação sugere que embora a atividade mitocondrial possa ser marcador de lesão hepática grave, não pode ser utilizada como marcador universal da lesão por isquemia e reperfusão do fígado canino.

\section{AGRADECIMENTOS}

Esse trabalho foi financiado em parte pela CAPES, Coordenação de Aperfeiçoamento de Pessoal de Nível Superior e FAPESP, Fundação de Amparo à Pesquisa do Estado de São Paulo, SP.

Miranda LEC, Viaro F, Ceneviva R, Évora PRB. Is the mitochondrial respiratory activity a good parameter for hepatic ischemia and reperfusion injury? Arq Gastroenterol 2005;42(2):89-94.

ABSTRACT - Background - Mitochondrial respiratory activity is associated with hepatic ischemia/reperfusion injury. Aim - To determine in vitro whether hepatic ischemia/reperfusion injury may be detected regardless mitochondrial respiratory activity. Material and Methods - Twenty-four heartworm-free mongrel dogs of either sex were randomized in the following groups: control, sham-operated dogs; $\mathrm{I}_{60}$, dogs subjected to 60 min of liver ischemia; $I_{30} / R_{60}$, dogs subjected to 30 min of ischemia e 60 min of reperfusion of liver; $I_{45} / R_{120}$ animals subjected to $45 \mathrm{~min}$ of ischemia and $120 \mathrm{~min}$ of reperfusion of liver. Blood and liver samples were taken after surgery to be processed. Mitochondrial respiratory activity was measured with a Clark-type oxygen electrode and mitochondrial membrane potential was calculated. lactic dehydrogenase, aspartate amino transferase and alanine aminotrasferase activities were determinated using laboratory kits, and malondialdehyde content in liver samples was estimated. Results - The group $\mathrm{I}_{45} / \mathrm{R}_{120}$ showed increases of serum aminotransferase, lactic dehydrogenase and malondialdehyde in liver samples. Whereas no changes were registered in mitochondrial respiratory activities and mitochondrial membrane potential, a tendency of decrease in the rate of active respiration (state 3) could be observed. Conclusion - Under the conditions of this study, the results suggest the data from mitochondrial respiratory activity could show no significance difference among groups in hepatic ischemia/reperfusion injury. Hepatic ischemia reperfusion injury can be detected regardless mitochondrial respiratory activity.

HEADINGS - Mitochondria, liver. Reperfusion injury. Oxidative phosphorylation. Liver. 


\section{REFERÊNCIAS BIBLIOGRÁFICAS}

1. Buege JA, Aust SD. Microsomal lipid peroxidation. Methods Enzymol 1978;52:302-10.

2. Chance B, Williams GR. Respiratory enzymes in oxidative phosphorylation. J Biol Chem 1955;217:409-27.

3. Colonna R, Massari S, Azzone GF. The problem of cation binding sites in the energized membrane of the intact mitochondria. Eur J Biochem 1973;34:577-85.

4. Cottart C-H, Do L, Blanc M-C, Vaubourdolle M, Descamps G, Durand D, Galen F-X, Clot J-P. Hepatoprotective effect of endogenous nitric oxide during ischema-reperfusion in the rat. Hepatology 1999;29:809-13.

5. Fulceri R, Bellomo G, Mirabelli F, Gamberucci A, Benedetti A. Measurement of mitochondrial and non-mitohondrial $\mathrm{Ca}++$ in isolated intact hepatocytes: a critical re-evaluation of the use of mitochondrial inibitors. Cell Calcium 1991;12:431-9.

6. Gonzáles-Flecha B, Cutrin JC, Boveris A. Time course and mechanism of oxidative stress and tissue damage in rat liver subjected to in vivo ischemia-reperfusion. J Clin Invest 1993;91:456-64.

7. Grisotto PC. Indicadores de atividade dos radicais livres de oxigênio e alterações da membrana celular em músculo esquelético de ratos submetidos à isquemia e reperfusão[dissertação]. Ribeirão Preto: Faculdade de Medicina de Ribeirão Preto da Universidade de São Paulo; 1998.

8. Hartung KJ, Jung K, Minda R, Kunz W. The mitochondrial respiratory function as indicator of the ischemic injury if the rat kidney. Biomed Biochim Acta 1985;44:1435-43.

9. Henderson JM. Liver transplantation and rejection: an overview. Hepatogastroenterolgy 1999;46(Supp1 2):1428-84.

10. Jaeschke H, Schini VB, Farhood A. Role of nitric oxide in the oxidant stress during ischemia/reperfusion injury of the liver. Life Sci 1992;50:1797-804.

11. Jaeschke H. Mechanisms of reperfusion injury after warm ischemia of the liver. $\mathrm{J}$ Hepatobiliary Pancreat Surg 1998;50:402-8.

12. Kaplan RS, Pedersen PL. Characterization of phosphate efflux pathways in rat liver mitochondrial. Biochem J 1983;212:279-88.

13. Kurokawa T, Nonami T, Harada A, Nakao A, Sugiyama S, Ozawa T, Takagi H. Effects of prostaglandin $\mathrm{E}_{1}$ on the recovery os ischemia-induced liver mitochondrial dysfunction in rats with cirrosis. Scand J Gastroenterol 1991;26:269-74
14. Lehninger AL, Nelson IL, Cox MM. Fosforilação oxidativa e fotofosforilação: In: Lehninger AL, Nelson IL, Cox MM. Princípios de bioquímica. $2^{\text {a }}$ ed. São Paulo: Sarvier; 2000.

15. Lowroy OH, Rosebrough NJ, Farr AL, Randall RJ. Protein measurement with the folin phenol reagent. J Biol Chem 1951;193:265-75.

16. MA NS. Changes in malondialdehyde contents in serum and tissues after ischemia and reperfusion of the bowel in dogs. Zhonghua Zheng Xing Shao Shang Wai Ke Za Zhi 1992;8:127-9

17. Mathews CK, van Holde KE. Biological; oxidations; electron transport and oxidative phosphorylation. In: Mathews CK, van Holde KE. Biochemistry. Redwood City: The Benjamin/Cummings Publishing; c1990. p. 504-37.

18. Mathews WR, Guido DM, Fisher MA, Jaeschke H. Lipid peroxidation as molecular mechanism of liver cell injury during reperfusion after ischemia. Free Radic Biol Med 1994; 16:763-70.

19. Olson MS. Bionergetics and oxidative metabolism. In: Devlin, T.M. editor. Textbook of biochemistry: with clinical correlation, $3^{\circ}$ ed. New York: Wiley-Liss, 1992.p. 237-89,

20. Starzl TE, Demetris AJ, Van Thiel D. Liver transplantation. N Eng J Med 1989;329:1014.

21. Suzuki S, Nakamura S, Koizumi T. The benefical effect of a prostaglandin $\mathrm{I}_{2}$ analog on ischemic rat liver. Transplantation 1991;52:979-83.

22. Yoshikawa T, Oyamada H, Ichikawa H, Naito Y, Ueda S, Tainaka K, Takemura T, Tanigawa $\mathrm{T}$, Sugino S, Kondo M. Role of active species and lipid peroxidation in liver injury induced by ischemia-reperfusion. Nippon Shokakibyo Gakkai Zasshi 1990;87:199-205. 